\title{
Influence of MgO and Hybrid Fiber on the Bonding Strength between Reactive Powder Concrete and Old Concrete
}

\author{
Mo Jinchuan, ${ }^{1}$ Ou Zhongwen, ${ }^{1}$ and Wang Yahui ${ }^{2}$ \\ ${ }^{1}$ Department of Chemical and Material Engineering, Logistical Engineering University, Chongqing 401311, China
}

${ }^{2}$ Laixi Municipal Bureau of Quality and Technical Supervision, Qingdao 266600, China

Correspondence should be addressed to Mo Jinchuan; 728500246@qq.com

Received 13 April 2016; Accepted 13 June 2016

Academic Editor: Robert Cerný

Copyright (C) 2016 Mo Jinchuan et al. This is an open access article distributed under the Creative Commons Attribution License, which permits unrestricted use, distribution, and reproduction in any medium, provided the original work is properly cited.

The reactive powder concrete (RPC) was used as concrete repair material in this paper. The influence of steel fiber, steel fiber $+\mathrm{MgO}$, and steel fiber $+\mathrm{MgO}+$ polypropylene fiber (PPF) on the mechanical properties of RPC repair materials and the splitting tensile strength between RPC and old concrete was studied. Influences of steel fiber, $\mathrm{MgO}$, and PPF on the splitting tensile strength were further examined by using scanning electronic microscopy (SEM) and drying shrinkage test. Results indicated that the compressive and flexural strength was improved with the increasing of steel fiber volume fraction. However, the bonding strength showed a trend from rise to decline with the increasing of steel fiber volume fraction. Although $\mathrm{MgO}$ caused mechanical performance degradation of RPC, it improved bonding strength between RPC and existing concrete. The influence of PPF on the mechanical properties of RPC was not obvious, whereas it further improved bonding strength by significantly reducing the early age shrinkage of RPC. Finally, the relationship of drying shrinkage and splitting tensile strength was studied, and the equation between the splitting tensile strength relative index and logarithm of drying shrinkage was obtained by function fitting.

\section{Introduction}

Reactive powder concrete (RPC) was a new type of super high strength performance cement based composite materials which was invented by French Bouygues company $[1,2]$ and used the Linear Packing Density Model (LPDM), Compressible Packing Model (CPM), and fiber reinforced technology. Compared with conventional concrete, the advantages of RPC were as follows. (1) Super high strength [3]: the weight of RPC structure dramatically reduced compared with the corresponding conventional concrete structures at the same loading condition [4]. This characteristic expanded the application range of RPC in high-rise buildings and largespan structures. (2) Excellent durability: the coarse aggregate was removed during the process of RPC preparation. The internal defects of RPC were greatly reduced because of the particle size distribution optimized and internal structure uniformity increased which is caused by coarse aggregate removed [5]. As a result, RPC had high resistance to deicing salts, freeze-thaw cycles, and aggressive environments. (3) High performance of impact behavior [6]: former research had been showing that the antipenetration performance of RPC was up to 3 times of C30 concrete [7], which made it have a broad application prospect in protective engineering and antiearthquake engineering. (4) Self-healing ability: the water-binder ratio of RPC materials was very low generally between 0.17 and 0.22 , so there was a significant amount of unhydrated cement in finished products which might provide a self-healing potential after the generation of crack [8]. (5) High performance of resistance to elevated temperature: researchers $[9,10]$ reported that the cubic and axial compressive strength of RPC increased first and then decreased with the elevated temperature. The RPC had excellent capacity in resistance to high temperature compared with normalstrength concrete.

At present, the study of the RPC mainly focused on its preparation technology, mechanical properties, durability, and performance of RPC elements. The literature of using $\mathrm{RPC}$ as concrete repair materials was rare. Lee et al. [11] had been using RPC as the repair material; the results indicated that the RPC material showed a good repair performance. However, due to the low water-binder ratio, the shrinkage 
TABLE 1: Chemical composition of cement.

\begin{tabular}{lcccccccc}
\hline & $\mathrm{CaO}$ & $\mathrm{SiO}_{2}$ & $\mathrm{Al}_{2} \mathrm{O}_{3}$ & $\mathrm{Fe}_{2} \mathrm{O}_{3}$ & $\mathrm{MgO}$ & $\mathrm{Na}_{2} \mathrm{O}$ & $\mathrm{SO}_{3}$ & $\mathrm{Loss}$ \\
\hline P.O425R & 61.13 & 21.43 & 5.24 & 3.78 & 2.08 & 0.78 & 2.24 & 3.32 \\
P.C325 & 55.82 & 26.39 & 4.23 & 3.11 & 3.02 & 0.71 & 2.45 & 4.27 \\
\hline
\end{tabular}

TABLE 2: The properties of different fibers.

\begin{tabular}{lcccccc}
\hline Code & Density $/ \mathrm{g} / \mathrm{cm}^{3}$ & Elasticity modulus/GPa & Tensile strength/MPa & Diameter/mm & Length/mm & Ductility $/ \%$ \\
\hline SF & 7.8 & $200-220$ & 2850 & $0.2-0.25$ & 13 & $3-4$ \\
PPF & 0.91 & $2.4-3.2$ & $365-600$ & 0.01 & 12 & $10-20$ \\
\hline
\end{tabular}

deformation of RPC was large. Its shrinkage deformation could not agree with the deformation of old concrete which led to the generating of internal stress. The concrete repair failed when cracks generating between RPC and old concrete caused by internal stress surpassed the interfacial bonding strength. The drying shrinkage reduced by adding a certain amount of steel fiber; however, the steel fiber had little effect on the early age shrinkage of RPC. In engineering practice, the early age shrinkage of concrete was mainly controlled by adding polypropylene fiber [12]. Therefore, it might be a good method to inhabit early age shrinkage and drying shrinkage of RPC by hybrid fibers. In addition to inhibiting shrinkage, compensating the shrinkage of RPC by adding expansion additives was another effective way. The compensation for shrinkage was mainly due to the volume expansion caused by the hydration of expansion additives. The literature about using $\mathrm{MgO}$ as concrete expansive agent was familiar [13]. For a long period, the cement containing calcined $\mathrm{MgO}$ as delayed expansive agent in China had been used for dam concrete to compensate for temperature shrinkage [14]. Compared with sulfoaluminate-type and CaO-type expansive additives, the hydration of $\mathrm{MgO}$ demanded less water, and the hydration products of $\mathrm{Mg}(\mathrm{OH})_{2}$ are more stable in cement paste [15]. Thus, the $\mathrm{MgO}$ expansive agent played a more important role in modern concrete. At present, using $\mathrm{MgO}$ as expansive additives to improve the shrinkage deformation of RPC was still very scarcely.

The objectives of this work were as follows: using RPC as concrete repair material to study the influence of steel fiber, $\mathrm{MgO}$ expansive agent, and polypropylene fiber on the bond strength between RPC and old concrete, to explain reasons of the differences of bonding strength by shrinkage test and the microstructure analysis.

\section{Materials and Mix Proportion}

2.1. Materials. The materials used in this work included Ordinary Portland Cement (OPC), Composite Portland Cement (CPC), silica fume, quartz sand, quartz flour, superplasticizer (SP), and water. The chemical composition of OPC and CPC was shown in Table 1.

The grain diameter of quartz flour was about $10 \mu \mathrm{m}$. It is in a form of white powder, produced in Shanghai. The majority of mixes were produced using fine river sand whose particle size is from 0.075 to $0.6 \mathrm{~mm}$. The water reducer used in this experiment was polycarboxylate superplasticizer and
TABLE 3: Mix proportion of old concrete $/ \mathrm{kg} / \mathrm{m}^{3}$.

\begin{tabular}{lcccc}
\hline Cement & Water & Sand & Aggregate & Water reducer \\
\hline 440 & 185 & 532 & 1243 & 22 \\
\hline
\end{tabular}

the water-reducing rate of it exceeded $35 \%$. Silica fume was supplied by Sanyuan Company in Gansu province which existed in pale blue powder form and contains more than $94 \%$ reactive silicon dioxide content. The specific surface area of it exceeded $25 \mathrm{~m}^{2} / \mathrm{g}$. The aggregate used for preparation of old concrete was gravel whose particle size was not more than $25 \mathrm{~mm}$. The sand used in the old concrete was medium sand. The $\mathrm{MgO}$ expansive agent used in this research was produced by Haicheng Company in Liaoning province, whose density was $3.389 \mathrm{~g} / \mathrm{cm}^{3}$ and fineness was $60-90 \mu \mathrm{m}$. The content of $\mathrm{MgO}$ was more than $85 \%$ in this production. The copper coated steel fiber (SF) and polypropylene fiber (PPF) used in this study were supplied by Boen Company in Jiangsu province. Their physical properties were provided in Table 2.

2.2. Mix Proportion. The cement used for old concrete was P.C325. The mix proportion of old concrete was shown in Table 3.

The cement used in RPC was P.O425R. The mix proportion of RPC was shown in Table 4.

The meanings of codes in this study were as follows: $\mathrm{M}$ on behalf of $\mathrm{MgO}$, S on behalf of the steel fiber, and $\mathrm{P}$ on behalf of polypropylene fiber. For example, the code M5S10P1 means that the dosage of $\mathrm{MgO}$ was $5 \%$ of the quality of cement, steel fiber volume fraction was $1.0 \%$, the polypropylene fiber volume fraction was $0.1 \%$, and so on.

\section{Experiment Method}

The RPC mixes were produced by a high speed mortar mixer in this experiment. At first, the cement, silica fume, quartz flour, quartz sand, and $\mathrm{MgO}$ should be put into the mixer for 3-minute dry mixing. The fiber should be added during the process of dry mixing. In order to make the fiber disperse uniformly, the dry mixing time should be prolonged as the volume fraction of fiber is increasing. After dry mixing, half volume water which contained half amount of water reducer was added during stirring process. The remaining water and water reducer would be added after $3 \mathrm{~min}$. At last, mix about $10 \mathrm{~min}$ and then pour it into the required moulds. 
TABLE 4: Mix proportion of RPC/kg/m³.

\begin{tabular}{|c|c|c|c|c|c|c|c|c|c|}
\hline Code & Cement & Silica fume & Quartz flour & Quartz sand & Water & SF & PPF & $\mathrm{MgO}$ & Water reducer \\
\hline Control & 800 & 200 & 320 & 880 & 200 & 0 & 0 & 0 & 30 \\
\hline S05 & 800 & 200 & 320 & 880 & 200 & 39 & 0 & 0 & 30 \\
\hline S10 & 800 & 200 & 320 & 880 & 200 & 78 & 0 & 0 & 30 \\
\hline S15 & 800 & 200 & 320 & 880 & 200 & 117 & 0 & 0 & 30 \\
\hline M5S05 & 800 & 200 & 320 & 880 & 200 & 39 & 0 & 40 & 31.2 \\
\hline M5S10 & 800 & 200 & 320 & 880 & 200 & 78 & 0 & 40 & 31.2 \\
\hline M5S15 & 800 & 200 & 320 & 880 & 200 & 117 & 0 & 40 & 31.2 \\
\hline M7S05 & 800 & 200 & 320 & 880 & 200 & 39 & 0 & 56 & 31.7 \\
\hline M7S10 & 800 & 200 & 320 & 880 & 200 & 78 & 0 & 56 & 31.7 \\
\hline M7S15 & 800 & 200 & 320 & 880 & 200 & 117 & 0 & 56 & 31.7 \\
\hline M9S05 & 800 & 200 & 320 & 880 & 200 & 39 & 0 & 72 & 32.2 \\
\hline M9S10 & 800 & 200 & 320 & 880 & 200 & 78 & 0 & 72 & 32.2 \\
\hline M9S15 & 800 & 200 & 320 & 880 & 200 & 117 & 0 & 72 & 32.2 \\
\hline M5S10P1 & 800 & 200 & 320 & 880 & 200 & 78 & 0.91 & 40 & 31.2 \\
\hline M5S10P2 & 800 & 200 & 320 & 880 & 200 & 78 & 1.82 & 40 & 31.2 \\
\hline M5S10P3 & 800 & 200 & 320 & 880 & 200 & 78 & 2.73 & 40 & 31.2 \\
\hline M7S10P1 & 800 & 200 & 320 & 880 & 200 & 78 & 0.91 & 56 & 31.7 \\
\hline M7S10P2 & 800 & 200 & 320 & 880 & 200 & 78 & 1.82 & 56 & 31.7 \\
\hline M7S10P3 & 800 & 200 & 320 & 880 & 200 & 78 & 2.73 & 56 & 31.7 \\
\hline M9S10P1 & 800 & 200 & 320 & 880 & 200 & 78 & 0.91 & 72 & 32.2 \\
\hline M9S10P2 & 800 & 200 & 320 & 880 & 200 & 78 & 1.82 & 72 & 32.2 \\
\hline M9S10P3 & 800 & 200 & 320 & 880 & 200 & 78 & 2.73 & 72 & 32.2 \\
\hline
\end{tabular}

For compressive and flexural test, $40 \mathrm{~mm} \times 40 \mathrm{~mm} \times 160 \mathrm{~mm}$ prism was cast for the compressive and flexural strength of RPC, using splitting tensile test to evaluate the bonding strength between RPC and old concrete. The dimension of old concrete was $100 \mathrm{~mm} \times 100 \mathrm{~mm} \times 50 \mathrm{~mm}$, and the age was 90 days. Before casting RPC, the interface should be handled as follows. At first, remove the laitance which exists in surface of superficial aggregate with metal wire brush. Then, chisel the bonding surface of existing concrete by bush hammer. At last, clean the bonding surface for splitting tensile test. The bonding surface needed to be wetted before pouring RPC into moulds. The samples should be cured for 7 days under standard conditions before demoulding. The splitting tensile strength of different samples would be tested in age of 7 days, 28 days, and 90 days. The diagram of splitting tensile test was shown in Figure 1.

The splitting tensile strength can be calculated as $f_{t}=$ $2 P / \pi A=0.637(P / A)$, where $P$ stands for splitting tensile failure load $(\mathrm{N})$ and $A$ stands for area of bonding surface $\left(\mathrm{mm}^{2}\right)$. The relative index $\beta$ can be calculated as $\beta=f_{t, a} / f_{t, n} \times$ $100 \%$. In this formula, $f_{t, a}$ stands for the splitting tensile strength between RPC and old concrete; $f_{t, n}$ stands for the splitting tensile strength of whole old concrete. The shrinkage performance of RPC repair materials had a great impact on the bonding strength between the new concrete and old concrete. Studying the drying shrinkage performance of RPC was a main objective of this research. For drying shrinkage test, $40 \mathrm{~mm} \times 40 \mathrm{~mm} \times 160 \mathrm{~mm}$ prisms were cast for the determination drying shrinkage of RPC according to GB/T 29417-2012. After casting, the specimens should be cured for 7

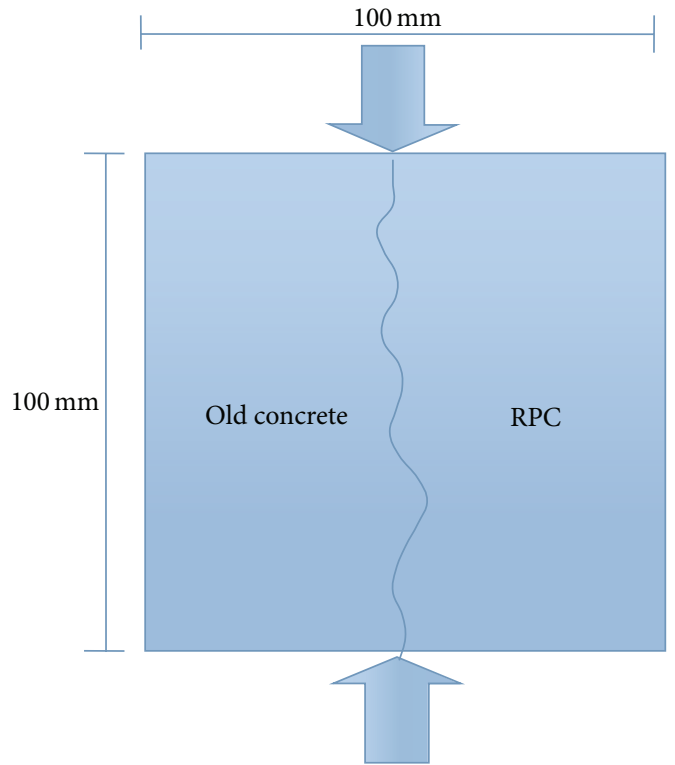

FIgURE 1: Schematic diagram of splitting tensile experiment.

days in standard curing box. The initial length of RPC should be tested after demoulding in test cabinet at $20 \pm 2{ }^{\circ} \mathrm{C}$ and relative humidity $60 \pm 5 \%$. Then all samples were stored in a controlled environment of $20 \pm 2^{\circ} \mathrm{C}$ and relative humidity $60 \pm 5 \%$ for subsequent measurement. The shrinkage strains were measured at $1,3,5,7,14,21,28,35,42,60$, and 90 days. 


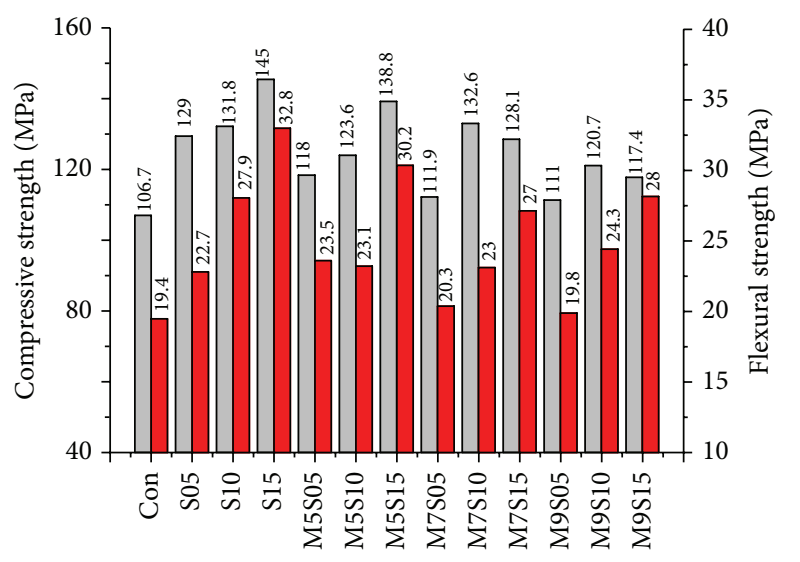

Compressive strength Flexural strength

FIGURE 2: Influence of $\mathrm{MgO}$ and steel fiber on mechanical properties of RPC.

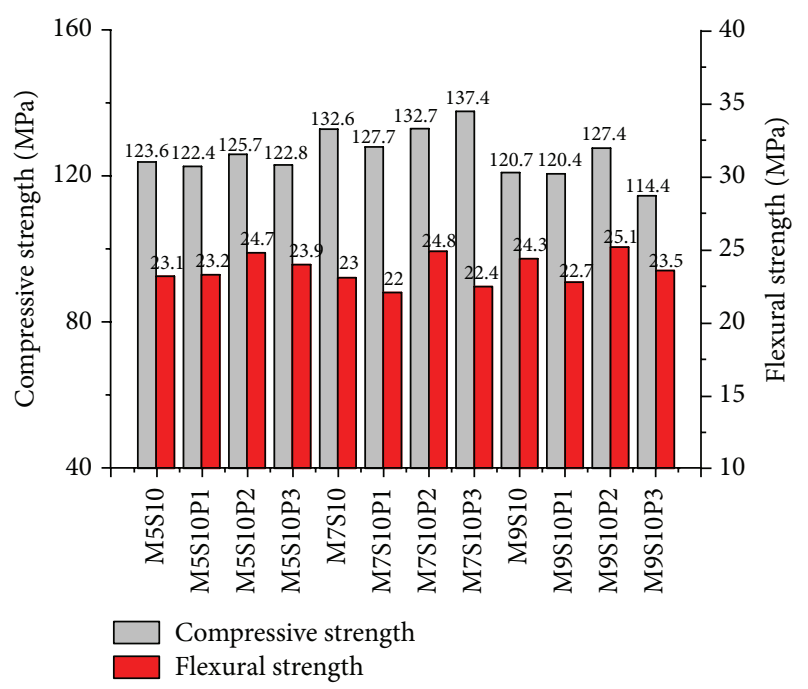

FIGURE 3: Influence of polypropylene fiber on mechanical properties of RPC.

\section{Results and Discussion}

4.1. Compressive and Flexural Strength of RPC. Compressive and flexural strength of each sample was as shown in Figures 2 and 3. According to the experiment results of this work, it was known that the presence of steel fiber and $\mathrm{MgO}$ had great influence on the compressive and flexural strength of RPC.

The use of steel fiber led to the improvement of the compressive and flexural strength of RPC while the use of $\mathrm{MgO}$ as expansion additives decreased strength of RPC. The main reason was that the steel fiber played a role of bridge and dowel in RPC [16]. The cohesive force between high elastic modulus steel fiber and cement matrix would act on a role of the resistance to crack when the load of RPC carried exceeded its ultimate load. So the compressive and flexural strength of RPC was elevated by adding steel fiber. The compressive and flexural strength obtained maximal value when the volume

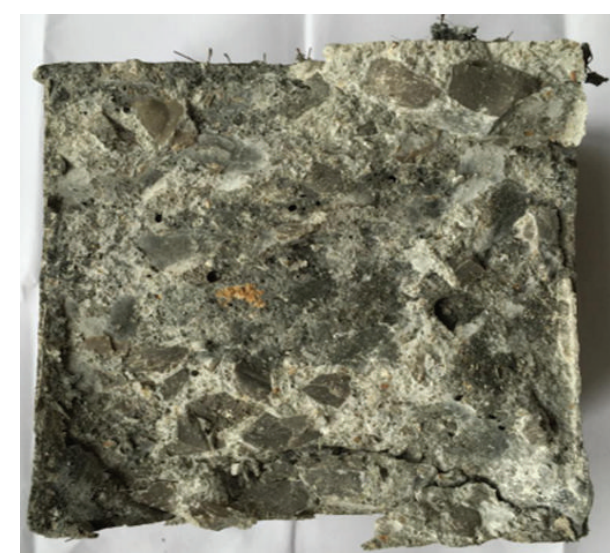

FIGURE 4: The side of RPC repair material.

fraction of steel fiber was $1.5 \%$. The value of S15 exceeded the sample-Con $36 \%$ and $69 \%$. However, the steel fiber began to reunion together and decreased the flowability of RPC significantly when the volume fraction attained $1.5 \%$. That is because the steel fiber took up some of mixing water; furthermore, there was not enough cement paste to wrap steel fiber and fill the gap with the increasing of steel fiber volume fraction. In addition, the steel fiber distributed randomly in three-dimensional RPC; the friction among the fibers increased with the increment of steel fiber which led to the decreasing of the RPC workability.

The mechanical strength of RPC declined with the dosage of $\mathrm{MgO}$ increasing. The compressive strength of M9S05 decreases $14 \%$ compared with S05 at $28 \mathrm{~d}$. The decreased values were $8.4 \%$ and $19 \%$ when the steel fiber volume fraction was $1.0 \%$ and $1.5 \%$, respectively. The variation tendency of flexural strength was likely to compressive strength. The reason for reduction in strength of RPC was that the hydration production C-S-H gel of RPC repair materials reduced as the content of cement reduced due to the increasing content of $\mathrm{MgO}$.

The influence of PPF on the mechanical strength was shown in Figure 4. The results indicated that the effect of PPF on the mechanical strength was small when the volume fraction of steel fiber is fixed at $1.0 \%$, and the dosage of $\mathrm{MgO}$ was the same. PPF was one of the polymer fibers with low elastic modulus and high ductility. It was difficult to undertake internal stress after RPC hardened. The elastic modulus of PPF used in this research was only about $3 \mathrm{GPa}$; this value was far less than the elastic modulus of the RPC. Thus, the main influencing factors of RPC mechanical property were volume fraction of steel fiber and dosage of $\mathrm{MgO}$.

4.2. Split Tensile Strength. The typical fracture surface of splitting tensile test was shown in Figures 4 and 5. Most of the failures occurred at the bonding surface between RPC and old concrete. This phenomenon indicated that the bonding surface was still the weakest link by using RPC as concrete repair material which was similar to other repair materials. 


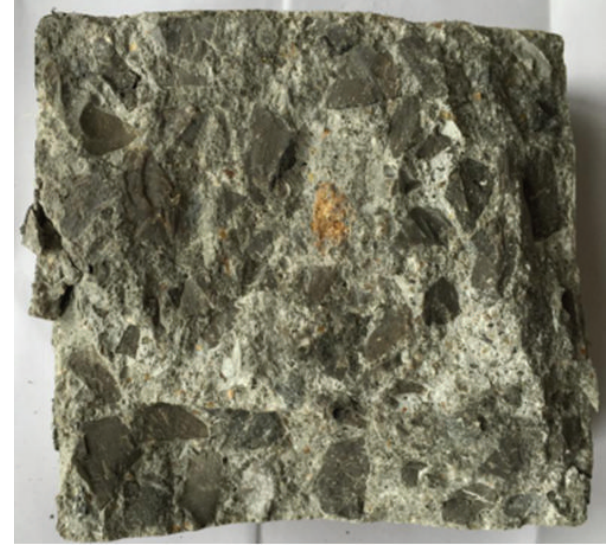

FIGURE 5: The side of old concrete.

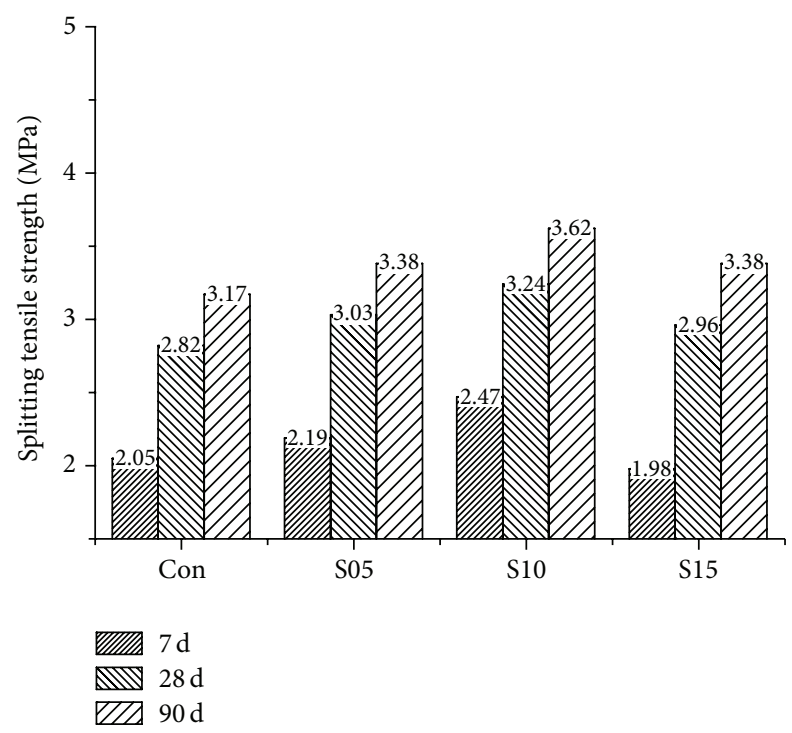

FIGURE 6: Influence of steel fiber on splitting tensile strength.

There was almost no damage to RPC repair material after splitting tensile strength test because the strength of RPC was much higher than old concrete. However, the old concrete was crushed normally, and some part of it was bonding to the RPC repair material side. This phenomenon indicated that the bonding strength was very high between RPC repair material and old concrete.

4.2.1. Influence of Steel Fiber on Splitting Tensile Strength. The splitting tensile strength of old concrete was $3.48 \mathrm{MPa}$ at 28 days. It could be found that RPC performed well at the concrete repair from Figure 6 . The value $\beta$ of every sample exceeded 0.8 at 28 days. This result was very closely to the splitting tensile strength of old concrete as a whole. However, the literature reported that the value $\beta$ of sample repaired with normal steel fiber enforced concrete was only 0.53 at 28 days [16]. The splitting tensile strength of samples with steel fiber were all higher than the control sample. However, splitting tensile strength showed a trend of decline after rising first with the increasing of steel fiber volume fraction. The splitting tensile strength of sample with $1.0 \%$ steel fiber reached peak at different age. At 7 days, the order of splitting tensile strength was $\mathrm{S} 10>\mathrm{S} 05>\mathrm{Con}>\mathrm{S} 15$; at 28 days the order was $\mathrm{S} 10>\mathrm{S} 05$ $>$ S15 > Con; at 90 days the order was S10 > S05 = S15 > Con. The splitting tensile strength declined significantly when the steel fiber volume fraction was $1.5 \%$. It was even lower than the samples with $0.5 \%$ steel fiber at 7 days and 28 days. The main reason as mentioned in 4.1 was that the workability and flowability became worse with the increasing of steel fiber volume fraction. There was not enough cement slurry to wrap steel fiber and fill the gap between the bonding surfaces.

4.2.2. Influence of $\mathrm{MgO}$ on Splitting Tensile Strength. Influence of $\mathrm{MgO}$ on the splitting tensile strength as shown in Figures 7(a)-7(c).

The influence of $\mathrm{MgO}$ on the splitting tensile strength was shown in Figure 7. The results indicated that splitting tensile strength of all samples improved considerably with the addition of $\mathrm{MgO}$. The splitting tensile strength showed a rising trend with the increasing of $\mathrm{MgO}$ content when steel fiber volume fraction was $0.5 \%$. The trend of group with $1.0 \%$ and $1.5 \%$ steel fiber was similar to that in Figure $7(a)$. This trend was contrary with the trend of the compressive and flexural strength. The main reason was that the shrinkage deformation of RPC was restrained by the swelling effects of $\mathrm{Mg}(\mathrm{OH})_{2}$ crystals which generated from the hydration of $\mathrm{MgO}$ [17]. The bonding strength increased because the swelling effect narrowed the gap of deformation between the RPC repaired materials and old concrete. The swelling effect was more obvious with the increasing of $\mathrm{MgO}$ which led to the higher splitting tensile strength under the condition of same steel fiber volume fraction. It also can be found that the splitting tensile strength raised at first then decreased with the increasing of steel fiber when the dosage of $\mathrm{MgO}$ was the same. The peak value was obtained when the steel fiber volume fraction reached $1.0 \%$. Therefore, in order to further research the influence of hybrid fiber composite $\mathrm{MgO}$ on splitting tensile strength, the volume fraction of steel fiber was fixed at $1.0 \%$ in next step.

4.2.3. Influence of PPF on the Splitting Tensile Strength. In Figures $8(\mathrm{a})-8(\mathrm{c})$, the addition of PPF improved the splitting tensile strength. At the beginning, the growth trend was slow; however, it became larger when the content of PPF was $0.3 \%$. The splitting tensile strength increased by $22.5 \%, 23.4 \%$, and $24.4 \%$ at 7 days, 28 days, and 90 days when the content of PPF was $0.3 \%$ as in Figure 8 (a). The growth rate was $27.5 \%, 28.2 \%$, and $29.6 \%$ as in Figure 8 (b) and $41.3 \%, 29.8 \%$, and $28.7 \%$ as in Figure $8(\mathrm{c})$. It could be found that the positive hybrid effect was produced between steel fiber and PPF from the above data. The method of hybrid fiber composite $\mathrm{MgO}$ expansion agent significantly improved the repairing effect of RPC.

4.3. Drying Shrinkage of RPC. The difference of deformation between RPC repair materials and old concrete was directly influenced by the drying shrinkage of RPC. The drying 


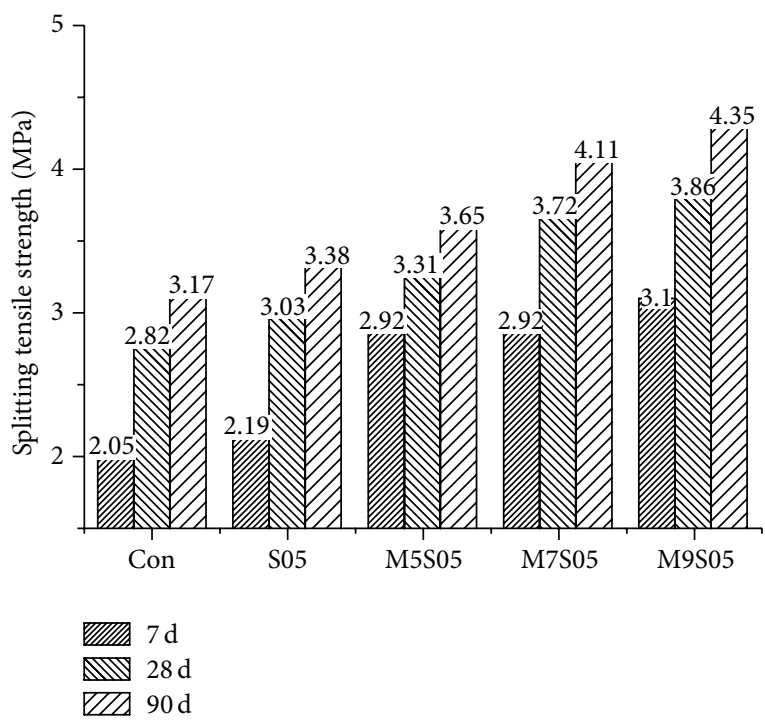

(a)

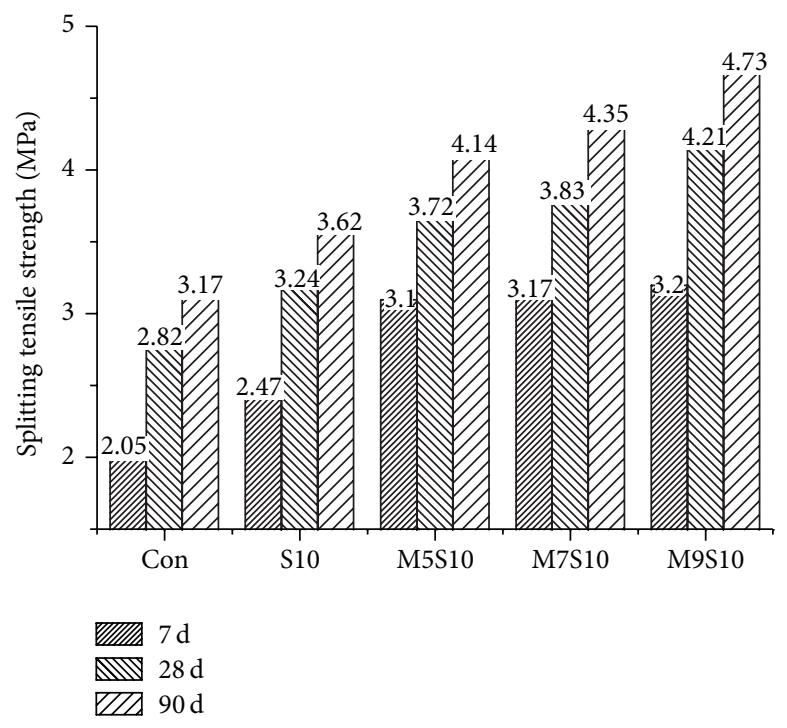

(b)

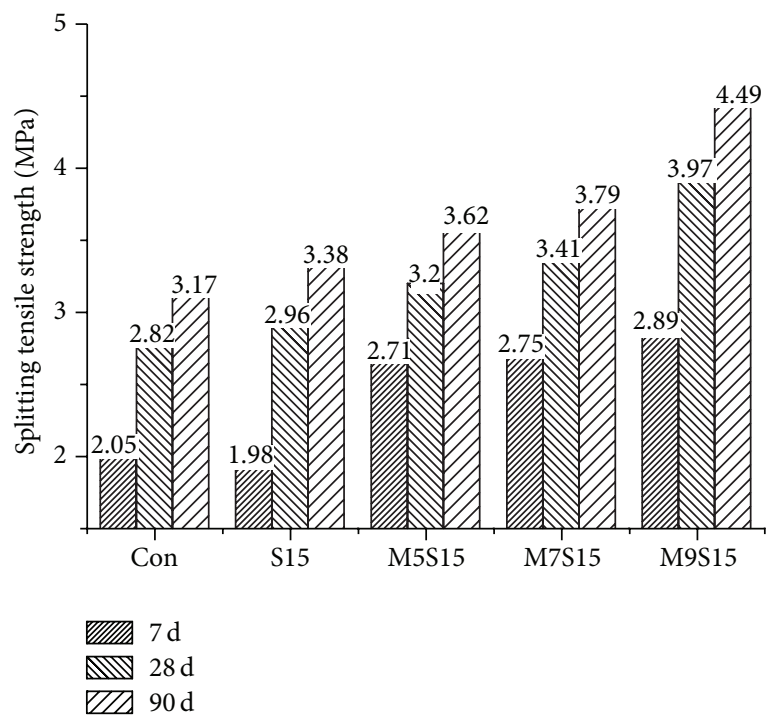

(c)

FIgURE 7: Influence of $\mathrm{MgO}$ on the splitting tensile strength.

shrinkage value of RPC at different ages in this experiment was tested.

4.3.1. Influence of Steel Fiber on the Drying Shrinkage of RPC Repair Materials. The change of shrinkage of RPC repair materials with the increasing of the steel fiber volume fraction was shown in Figure 9.

The drying shrinkage of RPC gradually reduced with the increasing of steel fiber volume fraction. The value of drying shrinkage had fallen by $4.7 \%, 19.1 \%$, and $31.4 \%$, respectively, with the increase of steel fiber volume fraction at 7 days. At 28 days the drying shrinkage value decreased by $15.9 \%$, $25.5 \%$ and $36.8 \%$, and at 90 days it reduced by $24.8 \%, 32.9 \%$, and $42.6 \%$, respectively. By observing the growth trend of the curve, the drying shrinkage of sample without steel fiber showed an obvious growth after 7 days. The drying shrinkage of control group increased $46.6 \%$ at 90 days compared with the value of 7 days. Although the drying shrinkage of samples with steel fiber also increased after 7 days, the growth trend was slower. The growth rate after 7 days was $15.6 \%, 21.4 \%$, and $22.8 \%$, respectively, when the volume fraction of steel fiber was $0.5 \%, 1.0 \%$, and $1.5 \%$. The drying shrinkage of RPC was significantly inhibited by the addition of steel from the above experimental data. The reason for drying shrinkage decreased was that the distribution of steel fiber showed a threedimensional random state, the skeleton structure was formed by the lap joint between steel fibers and coupled with high elastic modulus of steel fiber itself, and the inner stress of RPC which was generated from hardening RPC matrix shrinkage was partly compensated. Although the samples with $1.5 \%$ steel fiber showed the best performance of antishrinkage, the splitting tensile strength of it was still lower than the samples 


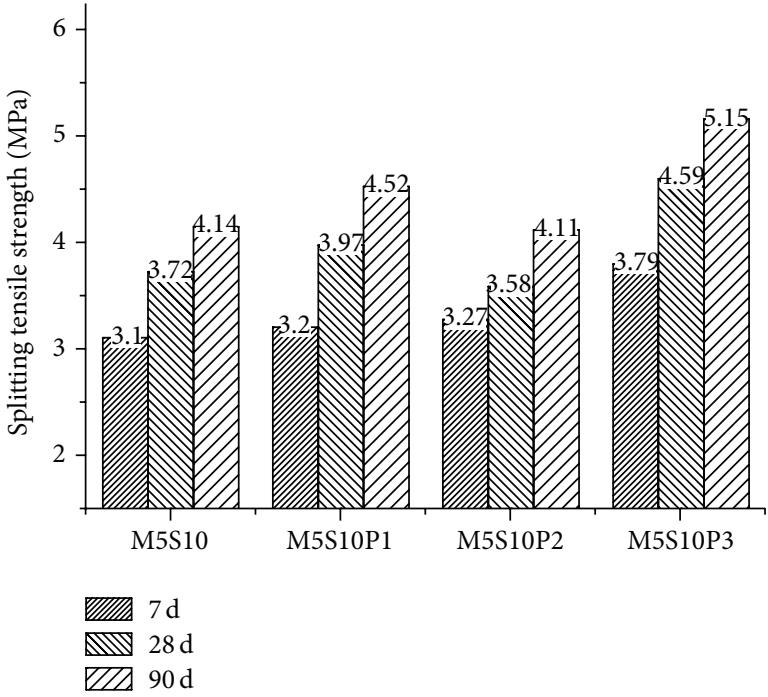

(a)

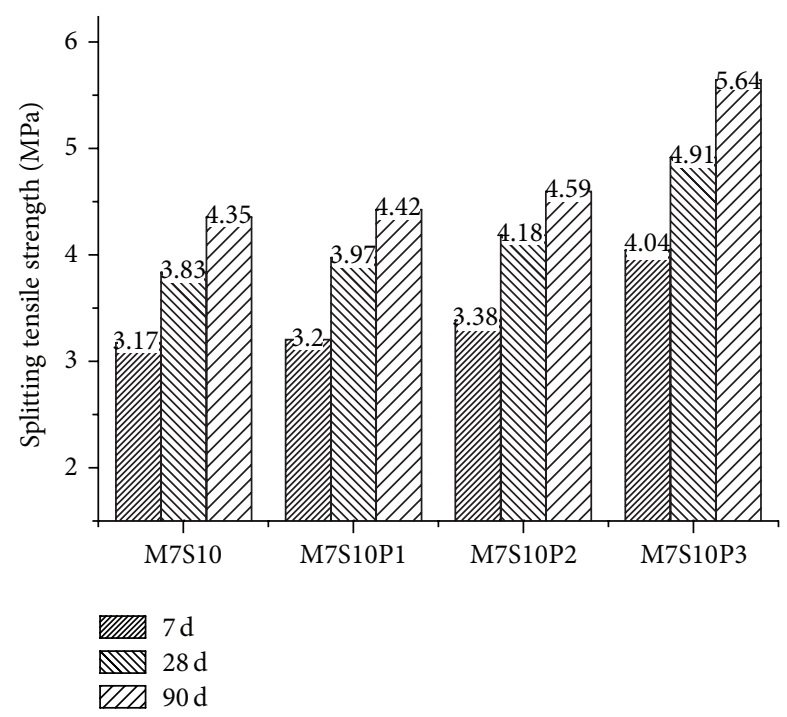

(b)

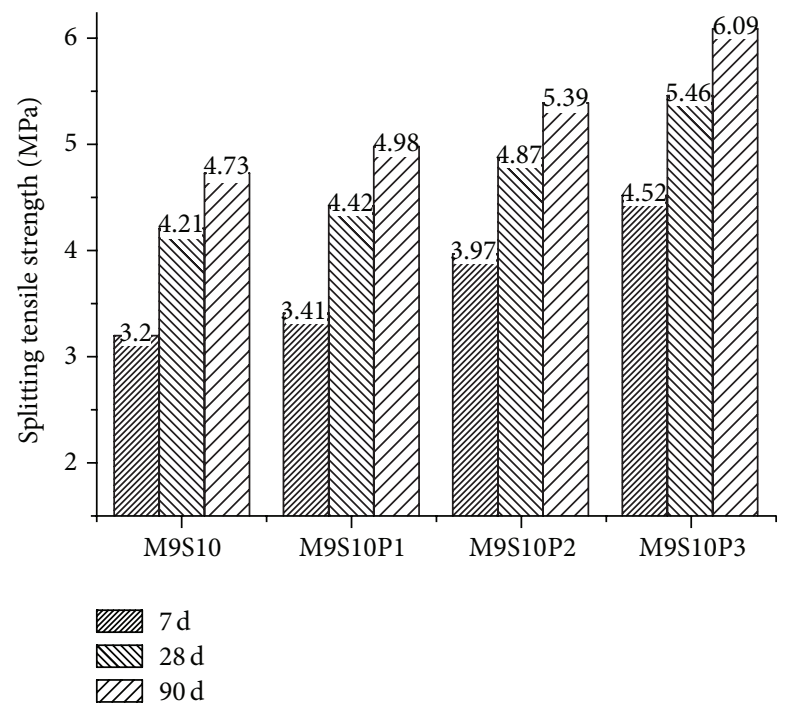

(c)

FIGURE 8: Influence of polypropylene fiber on the splitting tensile strength.

with $1.0 \%$ steel fiber which caused by the fiber reunion and workability reduced.

4.3.2. Influence of $M g O$ on Drying Shrinkage of RPC. Figures 10(a)-10(c) showed the influence of $\mathrm{MgO}$ on the drying shrinkage of RPC when the steel fiber volume fraction was $0.5 \%, 1.0 \%$, and $1.5 \%$, respectively.

The drying shrinkage reduced with the increase of dosage of $\mathrm{MgO}$ when the volume fraction of steel fiber was fixed from Figure 10. Compared with group S05, the drying shrinkage reduced by $8.9 \%, 18 \%$, and $31.5 \%$, respectively, with the increase of $\mathrm{MgO}$ in Figure 10(a). In Figure 10(b), the value reduced by $12.4 \%, 14.6 \%$, and $33 \%$ compared with group $\$ 10$. In Figure 10(c), the value reduced by $11.1 \%, 20.4 \%$, and $35.2 \%$ compared with group S15. The experiment results indicated that the drying shrinkage of RPC was inhabited by MgO. The reason was that $\mathrm{Mg}(\mathrm{OH})_{2}$ generated from the hydration of $\mathrm{MgO}$ caused the volume expansion. Researcher reported that the volume could swell $118 \%$ during the hydration of $\mathrm{MgO}$. At the same time, the pressure caused by the growth process of $\mathrm{Mg}(\mathrm{OH})_{2}$ crystal also leads to the expansion of the cement matrix. With the increase of dosage of $\mathrm{MgO}$, more $\mathrm{Mg}(\mathrm{OH})_{2}$ is generated which caused greater expansion pressure for the cement matrix. So the drying shrinkage continued to reduce with the increase of dosage of $\mathrm{MgO}$. However, the deformation of RPC repair materials was decided by the competition between the hydration of $\mathrm{MgO}$ and cement [18]. Theoretically, only under the condition of the ratio of water $/ \mathrm{MgO}$ exceeding 0.45 could the $\mathrm{MgO}$ completely hydrate. The ratio of water/binder was only 0.2 in this experiment, and there was not enough water for the hydration of $\mathrm{MgO}$, and so the drying shrinkage of RPC could only be partially compensated. That was different from general 


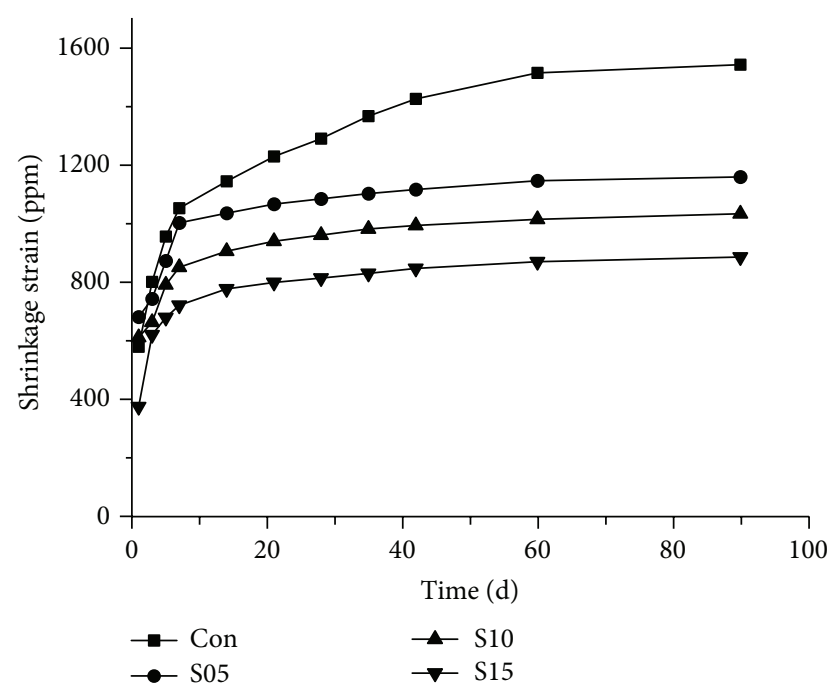

FIGURE 9: Influence of steel fiber on the drying shrinkage property of RPC.

$\mathrm{MgO}$ concrete; the $\mathrm{MgO}$ content could hydrate completely in common magnesia concrete because water cement ratio was higher which could provide sufficient water for hydration reaction of $\mathrm{MgO}$. Under this condition, the addition of $\mathrm{MgO}$ not only could compensate the early age shrinkage caused by cement hydration, but also even formed a microexpansion effect.

4.3.3. Influence of PPF on the Drying Shrinkage of RPC. The elastic modulus of PPF was far lower than the steel fiber; the enforcement effect for concrete of it was not obvious. However, some literature reported that it could effectively reduce the early age shrinkage of concrete. Therefore, in order to achieve the goal of inhibiting the ultimate shrinkage of RPC, the measures of mix steel fiber with PPF for RPC repair materials should be considered. Figures 11(a)-11(c) showed that the influence of PPF mixed with steel fiber on the drying shrinkage of RPC under the condition of the content of $\mathrm{MgO}$ was the same.

As shown in Figures 11(a)-11(c), the drying shrinkage of RPC continuously reduced with the increasing of PPF when the volume fraction of steel fiber and dosage of $\mathrm{MgO}$ were the same. The drying shrinkage reduced obviously at 90 days after the PPF blended with steel fiber. The drying shrinkage gradually decreased with the increase of PPF volume fraction. The drying shrinkage reduced by $18.5 \%, 28.1 \%$, and $33.3 \%$, respectively, with the increase of PPF compared with group M5S10 in Figure 11(a). In Figure 11(b), the value reduced by $24.1 \%, 29.6 \%$, and $34.7 \%$, respectively, compared with group M7S10. In Figure 11(c), the value reduced by $16.3 \%, 26.3 \%$, and $39.3 \%$, respectively, compared with group M9S10. The experiment results indicated that the steel fiber and PPF showed obvious positive hybrid effect for drying shrinkage of RPC repair material. There were more single fibers for PPF per unit mass because of the density of which was small, so it could combine closely with the cement matrix. After being blended with steel fiber, the PPF was distributed more uniformly and formed a three-dimensional interleaving support network in the RPC repair material. The early age shrinkage of RPC was reduced by PPF because the pore structure of RPC was further improved, the bleeding path was reduced, and the capillary stress was dispersed and reduced too [19]. Because of the hardening of cement matrix and the increasing of strength, the bonding strength between the fiber and concrete substrate strengthened gradually and the tensile stress was mainly undertaken by the high elastic modulus of steel fiber; thus different elastic modulus of steel fiber and PP fiber played different roles of inhibition of shrinkage at the different hydration stage of RPC. By decreasing the early age shrinkage, the final shrinkage value of RPC repair materials was further reduced by PPF.

The hybrid fiber also improved the pore structure and minimized the pore size of RPC at different scales and different levels in three dimensions. The uniformity of RPC was further improved; as a result, the moisture escaping was effectively inhibited and the stress of capillary was reduced too. At the same time, the fiber with different elastic modulus dispersed the contraction stress in different periods of hydration of RPC, the local stress concentration phenomenon was prevented, and at last the shrinkage performance of RPC was greatly improved.

4.4. Microstructure of RPC. The morphology of fibers in RPC was shown in Figures 12(a)-12(b). It was visible in Figure 12(a) that the steel fiber was tightly bound with the matrix of RPC, and the bond stress between them was large, which could in some extent counteract the drying shrinkage and internal tensile stress of RPC. Figure 12(b) indicated that the PPF is present in a form of leaf shape and its cross-sectional area was far less than that of steel fiber. The number of PPF per unit mass was more than that of steel fiber which caused more firmly anchorage with RPC matrix and more closely self-locking overlap between the fibers. As a result, the final shrinkage values of RPC could be further reduced by the mixed PPF on the basis of steel fiber.

The microstructure of $\mathrm{MgO}$ and the hydration product of it were shown in Figures 13(a)-13(b). MgO was in a flocculent form whose particle size was small. What is more, SEM analysis indicated that morphology of $\mathrm{MgO}$ particle was mostly anomalistic body, the surface of which was coarse and lax structure. According to this phenomenon, it might be speculated that the hydration activity of $\mathrm{MgO}$ was high. Figure 13(b) showed that the hydration product of $\mathrm{MgO}$ after $1 \mathrm{~d}$ under the condition of water to binder ratio was 0.45 . It was found that the morphology of $\mathrm{MgO}$ changed obviously, and more flaky $\mathrm{Mg}(\mathrm{OH})_{2}$ was formed, which indicated that the hydration of it was fast, and the volume was also swelled. Therefore, the addition of $\mathrm{MgO}$ could obviously inhibit the shrinkage of RPC.

In Figures $14(\mathrm{a})-14(\mathrm{~b}), \mathrm{Mg}(\mathrm{OH})_{2}$ was wrapped by the hydration products of cement in RPC. The white dotted area was $\mathrm{Mg}(\mathrm{OH})_{2}$ crystals, and the needle-like crystals in Figure 14(a) were AFt. Hydration product of $\mathrm{Mg}(\mathrm{OH})_{2}$ formed around the $\mathrm{MgO}$ particles and filled the pores inside the RPC. The volume expansion was caused by the hydration 


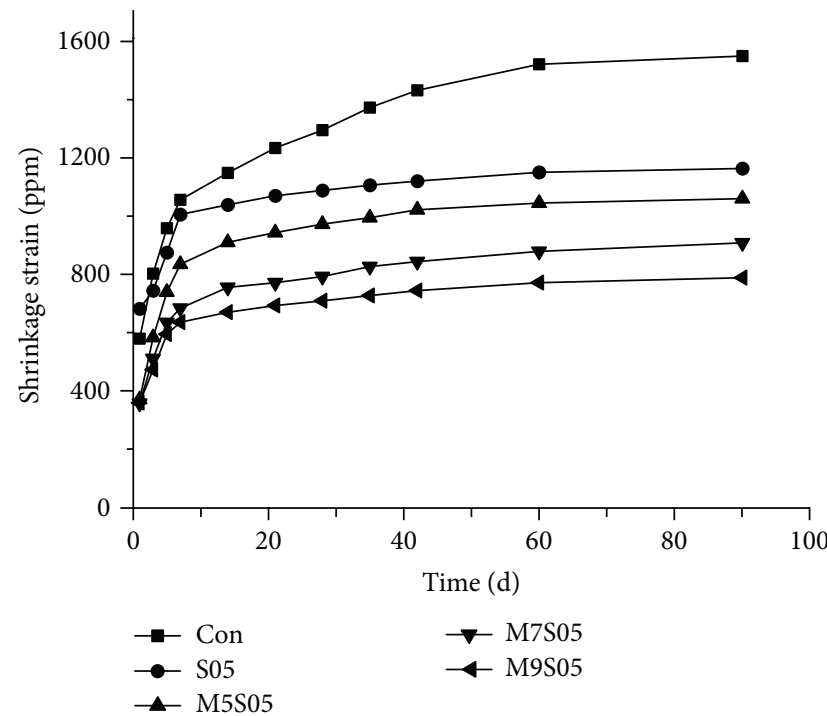

(a)

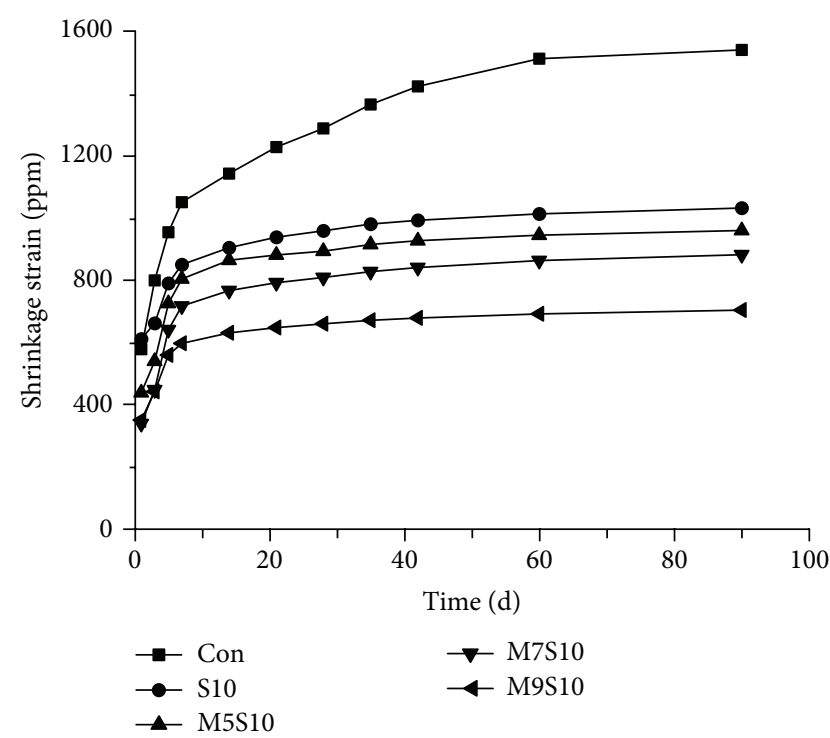

(b)

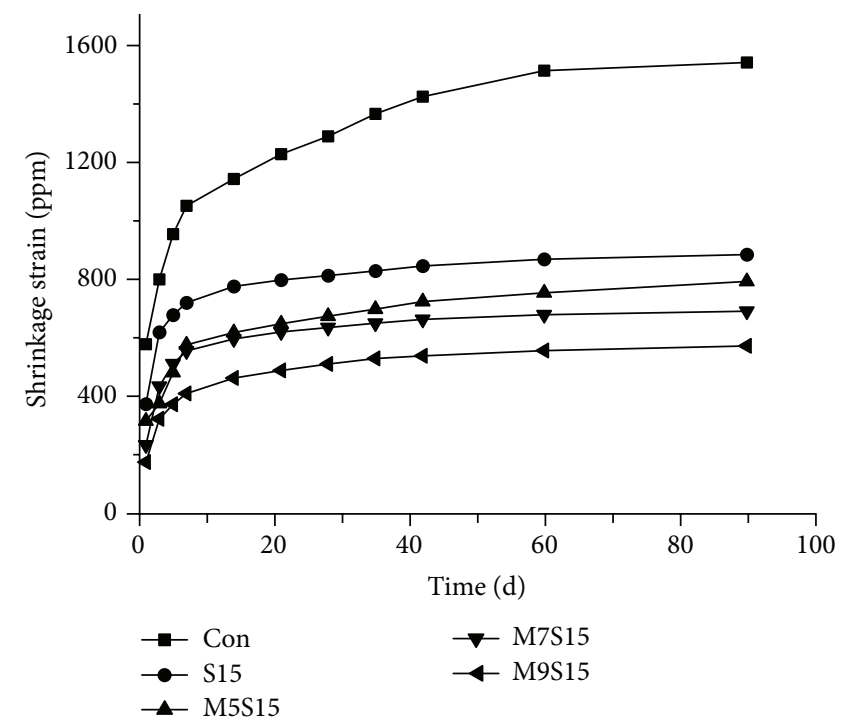

(c)

FIGURE 10: Influence of MgO on the drying shrinkage property of RPC.

of $\mathrm{MgO}$ particles. During this procedure, the large expansion pressure and $\mathrm{Mg}(\mathrm{OH})_{2}$ crystal growth pressure were caused because of the restriction of the cement matrix which led to the expansion of the matrix of RPC. Therefore, the shrinkage of RPC decreased as the addition of $\mathrm{MgO}$ is increasing. The $\mathrm{Mg}(\mathrm{OH})_{2}$ crystal mainly existed around the $\mathrm{MgO}$ particles. Because the internal of RPC was a strong alkaline environment, it had a strong influence on the solubility, hydration degree, nucleation site, crystal growth, and morphology of $\mathrm{Mg}(\mathrm{OH})_{2}$. Due to the high concentration of $\mathrm{OH}^{-}$in $\mathrm{RPC}$ pore solution, the diffusion of $\mathrm{Mg}^{2+}$ was limited during the process of hydration. As a result, the supersaturated solution of $\mathrm{OH}^{-}$ and $\mathrm{Mg}^{2+}$ could only be formed around the hydration region of $\mathrm{MgO}$ which caused $\mathrm{Mg}(\mathrm{OH})_{2}$ to firstly generate around the $\mathrm{MgO}$ particles and form a layer. With the increasing of age, water should pass through $\mathrm{Mg}(\mathrm{OH})_{2}$ layer to continue the hydration reaction. Therefore, the shrinkage compensation of $\mathrm{MgO}$ was large in the early stage of hydration and reduced at increasing of age.

4.5. The Relationship between Shrinkage Value and Splitting Tensile Strength. The bonding strength was greatly influenced by the internal stress caused by the difference of deformation between repair materials and old concrete. This effect was directly reflected in the splitting tensile strength between RPC repair materials and old concrete. In this experiment, the age of old concrete had been exceeding 90 days, so the deformation had been basically stable. The shrinkage deformation of RPC repair material should be approximately considered as the deformation differences 


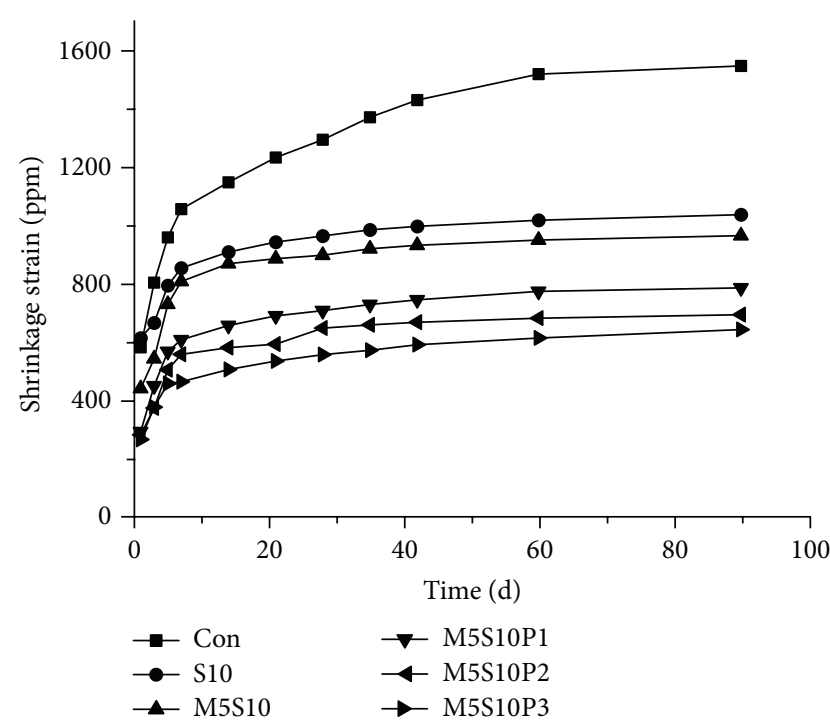

(a)

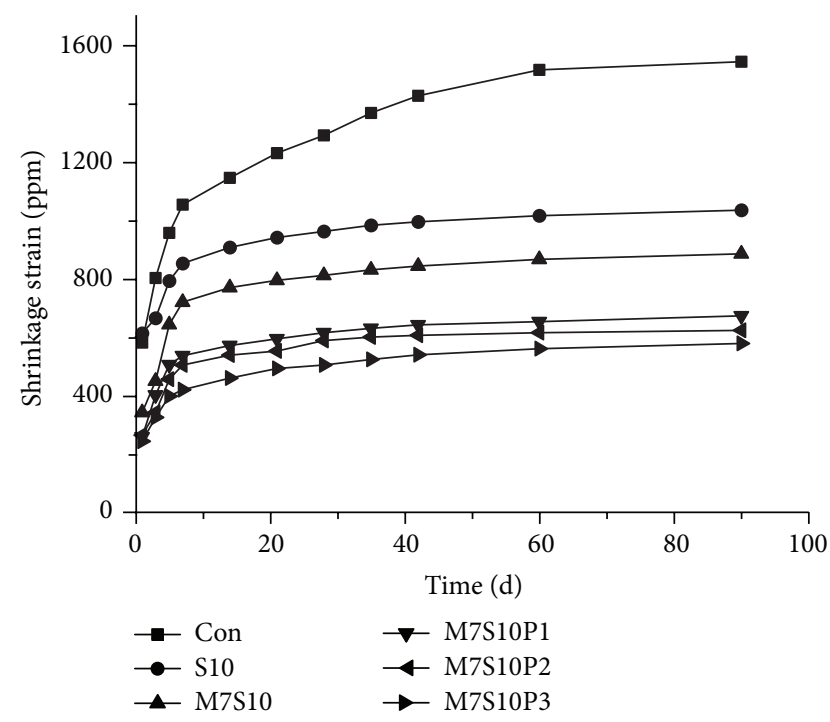

(b)

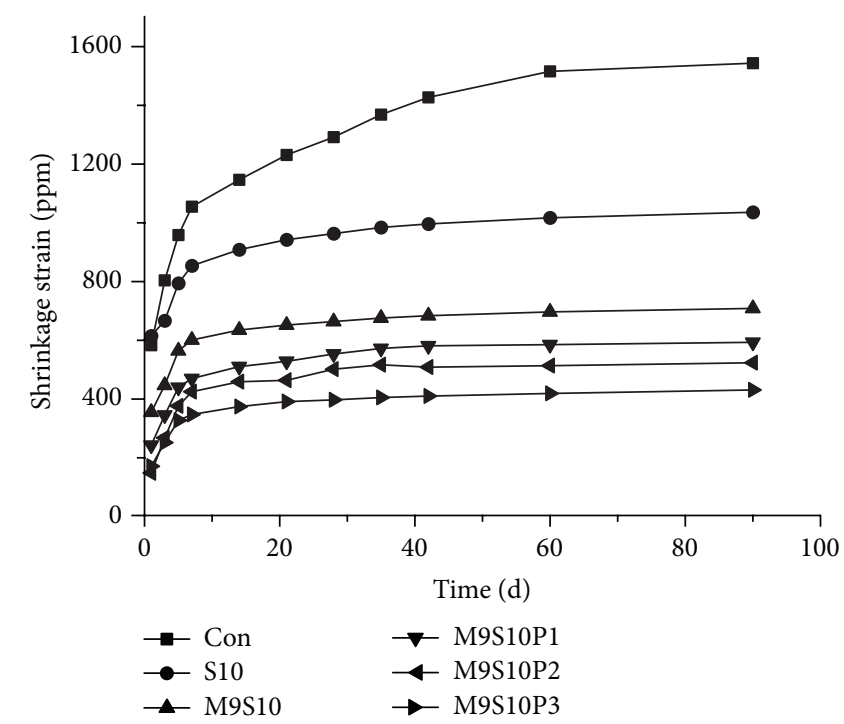

(c)

FIGURE 11: Influence of polypropylene fiber on the drying shrinkage property of RPC.

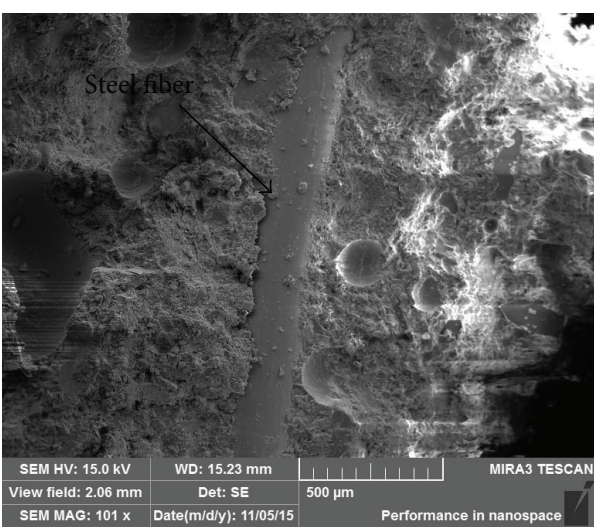

(a)

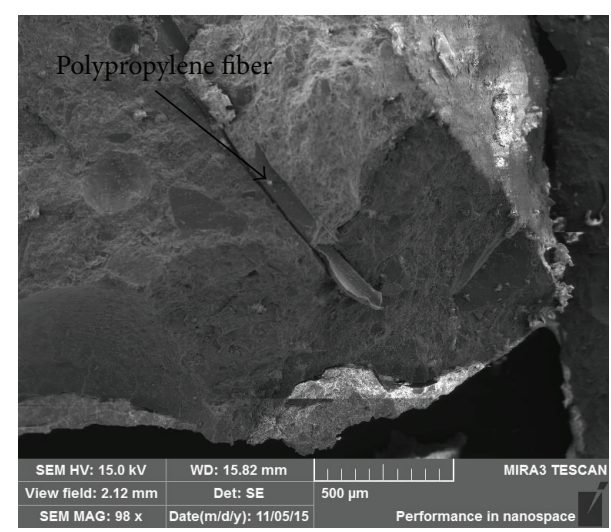

(b)

FIGURE 12: The microscopic morphology of fiber in RPC. 


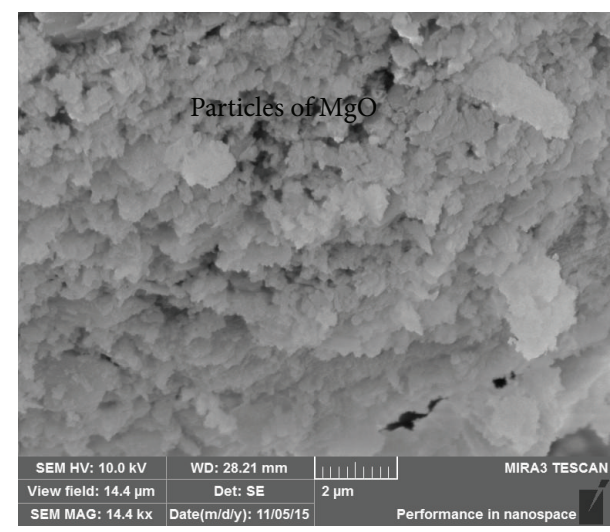

(a)

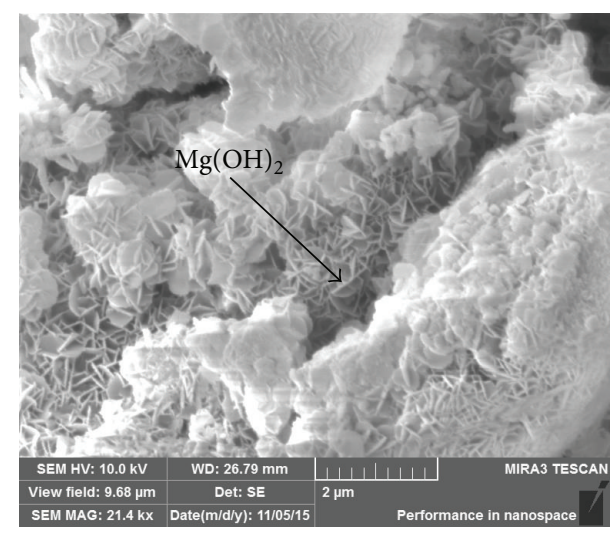

(b)

FIgURE 13: Microstructure of $\mathrm{MgO}$ and hydration products of it.

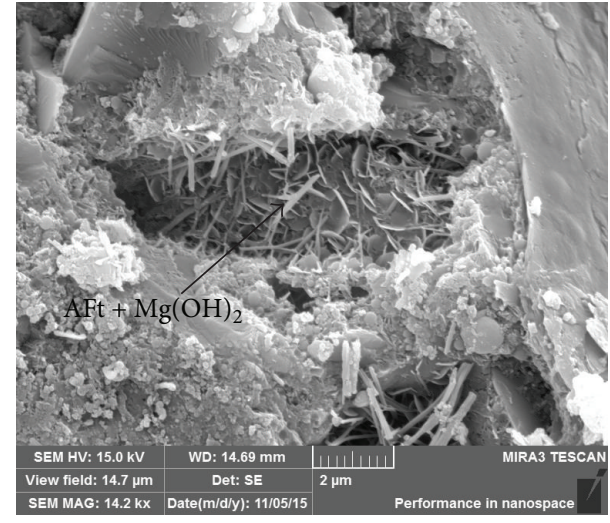

(a)

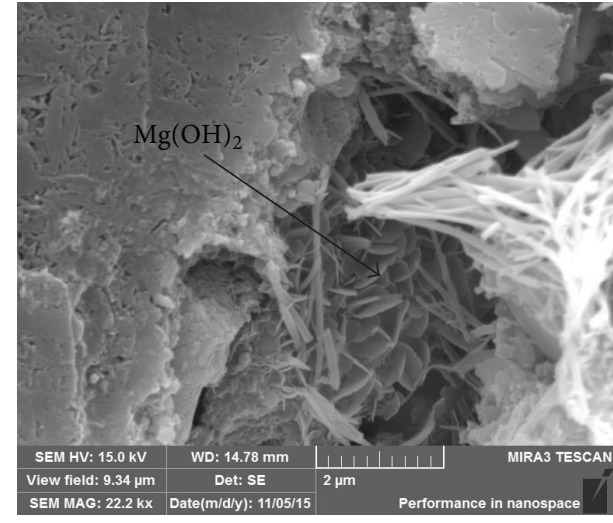

(b)

FIGURE 14: Microstructure of RPC.

between RPC and old concrete. The relationship between the RPC repair material shrinkage rate and the splitting tensile relative index was studied in this part. Although the drying shrinkage of RPC with $1.5 \%$ steel fiber was lowest, the splitting tensile strength on the contrary was lower because of the agglomeration of steel fiber. Therefore, the group with $1.5 \%$ steel fiber should be eliminating when to study the relationship between drying shrinkage and splitting tensile strength. The logarithm of shrinkage value as the abscissa, the value $\beta$ as the ordinate, and the relationship between them were shown in Figure 15.

According to fitting result, the relationship between splitting tensile relative index and shrinkage rate was shown in

$$
Y=1.45 \log (x)+5.26, \quad 28 \mathrm{~d} R=0.898 .
$$

As shown in (1), the splitting tensile relative index reduced greatly as the shrinkage decreased.

\section{Conclusion}

In this paper, the RPC was used as concrete repair material, and the influence of hybrid fiber mixed with $\mathrm{MgO}$ on the splitting tensile strength between RPC and old concrete was studied. Moreover, the drying shrinkage deformation of RPC was studied too. Through this research, adopting the method of hybrid fibers mixing with $\mathrm{MgO}$ significantly reduced the shrinkage of the RPC, which greatly improved the bonding stress between RPC and old concrete. The conclusions of this research were as follows:

(1) The compressive and flexural strength of RPC increased with the content of steel fiber increasing. The addition of $\mathrm{MgO}$ reduced the mechanical strength of RPC, and the compressive and flexural strength decreased with the increasing of dosage of $\mathrm{MgO}$. PPF had no obvious effect on the mechanical properties of RPC.

(2) RPC displayed excellent repair potentials and possessed high bonding strength with old concrete. The splitting tensile strength reached peak when the steel fiber volume fraction was $1.0 \%$. However, steel fiber began to reunion when the volume rate came to $1.5 \%$ which caused the splitting tensile strength to decrease.

(3) The volume expansion caused by hydration of $\mathrm{MgO}$ partly compensated the shrinkage of RPC, which 


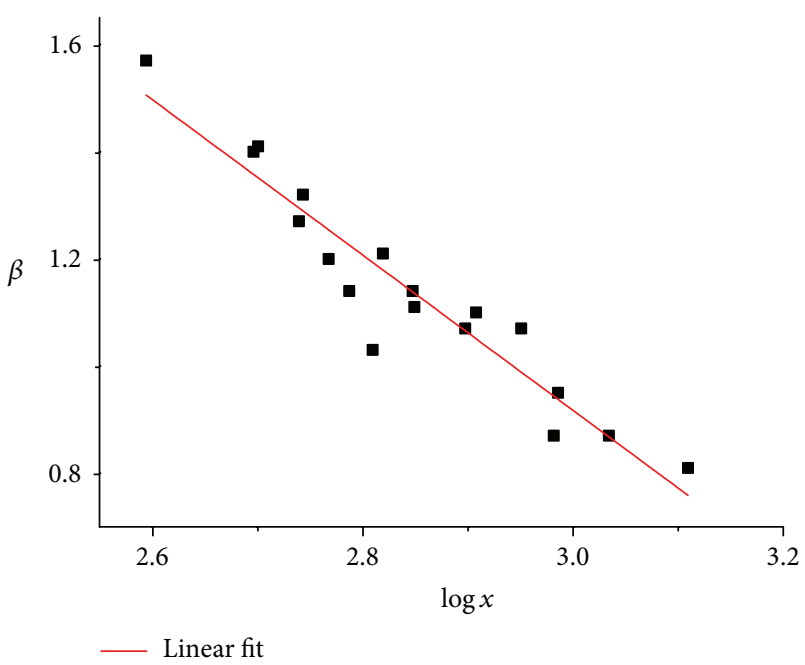

Figure 15: Relationship between $\beta$ and the logarithm of drying shrinkage ratio.

led to the increasing of splitting tensile strength. Although the addition of $\mathrm{MgO}$ reduced the mechanical properties of RPC, it played a positive role for the bonding strength between RPC and old concrete.

(4) Blending PPF on the basis of steel fiber and $\mathrm{MgO}$ reduced the early shrinkage of RPC repair materials; as a result the ultimate shrinkage of RPC repair material was further reduced and the bonding strength was further improved too. The PPF and steel fiber showed obvious positive hybrid effect.

(5) The relationship between shrinkage rate of RPC and splitting tensile strength was studied. It showed an obvious linear relationship between tensile splitting relative index and logarithm of shrinkage rate. The splitting tensile relative index decreased gradually with the increasing of shrinkage rate.

\section{Competing Interests}

The authors declare that there are no competing interests regarding the publication of this paper.

\section{Acknowledgments}

The authors want to thank the Chinese National Science Foundation Project of CQ CSTC (cstc2015jcyjA30005, cstc2014jcyjA50026) and Chongqing Graduate Student Innovation Project under Grant no. CYB14103 for financial support.

\section{References}

[1] P. Richard and M. Cheyrezy, "Composition of reactive powder concretes," Cement and Concrete Research, vol. 25, no. 7, pp. 1501-1511, 1995.
[2] M. Cheyrezy, V. Maret, and L. Frouin, "Microstructural analysis of RPC (Reactive Powder Concrete)," Cement and Concrete Research, vol. 25, no. 7, pp. 1491-1500, 1995.

[3] J. Song and S. Liu, "Properties of reactive powder concrete and its application in highway bridge," Advances in Materials Science and Engineering, vol. 2016, Article ID 5460241, 7 pages, 2016.

[4] L. Huynh, S. Foster, H. Valipour, and R. Randall, "High strength and reactive powder concrete columns subjected to impact: experimental investigation," Construction and Building Materials, vol. 78, pp. 153-171, 2015.

[5] H. Yazici, H. Yigiter, A. Ş. Karabulut, and B. Baradan, "Utilization of fly ash and ground granulated blast furnace slag as an alternative silica source in reactive powder concrete," Fuel, vol. 87, no. 12, pp. 2401-2407, 2008.

[6] Y. Wang, Z. Wang, X. Liang, and M. An, "Experimental and numerical studies on dynamic compressive behavior of reactive powder concretes," Acta Mechanica Solida Sinica, vol. 21, no. 5, pp. 420-430, 2008.

[7] T. Ge, Y. Pan, K. Tan, and M. Wang, "Study on resistance of reactive powder concrete to impact," Chinese Journal of Rock Mechanics and Engineering, vol. 26, supplement 1, pp. 35533557, 2007.

[8] C. M. Tam, V. W. Y. Tam, and K. M. Ng, "Assessing drying shrinkage and water permeability of reactive powder concrete produced in Hong Kong," Construction and Building Materials, vol. 26, no. 1, pp. 79-89, 2012.

[9] G.-F. Peng, Y.-R. Kang, Y.-Z. Huang, X.-P. Liu, and Q. Chen, "Experimental research on fire resistance of reactive powder concrete," Advances in Materials Science and Engineering, vol. 2012, Article ID 860303, 6 pages, 2012.

[10] Y.-S. Tai, H.-H. Pan, and Y.-N. Kung, "Mechanical properties of steel fiber reinforced reactive powder concrete following exposure to high temperature reaching $800^{\circ} \mathrm{c}$," Nuclear Engineering and Design, vol. 241, no. 7, pp. 2416-2424, 2011.

[11] M.-G. Lee, Y.-C. Wang, and C.-T. Chiu, "A preliminary study of reactive powder concrete as a new repair material," Construction and Building Materials, vol. 21, no. 1, pp. 182-189, 2007.

[12] S. P. Yap, C. H. Bu, U. J. Alengaram, K. H. Mo, and M. Z. Jumaat, "Flexural toughness characteristics of steelpolypropylene hybrid fibre-reinforced oil palm shell concrete," Materials and Design, vol. 57, pp. 652-659, 2014.

[13] F. Jin, K. Gu, and A. Al-Tabbaa, "Strength and hydration properties of reactive $\mathrm{MgO}$-activated ground granulated blastfurnace slag paste," Cement and Concrete Composites, vol. 57, pp. 8-16, 2015.

[14] L. Mo, M. Deng, M. Tang, and A. Al-Tabbaa, "MgO expansive cement and concrete in China: past, present and future," Cement and Concrete Research, vol. 57, pp. 1-12, 2014.

[15] P.-W. Gao, S.-Y. Xu, X. Chen, J. Li, and X.-L. Lu, "Research on autogenous volume deformation of concrete with $\mathrm{MgO}$," Construction and Building Materials, vol. 40, pp. 998-1001, 2013.

[16] D.-Y. Gao, H.-Q. Cheng, and H.-T. Zhu, "Splitting tensile bonding strength of steel fiber reinforced concrete to old concrete," Journal of Building Materials, vol. 10, no. 5, pp. 505509, 2007 (Chinese).

[17] Y.-H. Fang, J.-F. Liu, and Y.-Q. Chen, "Effect of magnesia on properties and microstructure of alkali-activated slag cement," Water Science and Engineering, vol. 4, no. 4, pp. 463-469, 2011.

[18] L. Mo, M. Deng, and M. Tang, "Effects of calcination condition on expansion property of $\mathrm{MgO}$-type expansive agent used in cement-based materials," Cement and Concrete Research, vol. 40, no. 3, pp. 437-446, 2010. 
[19] W. Sun, H. Chen, X. Luo, and H. Qian, "The effect of hybrid fibers and expansive agent on the shrinkage and permeability of high-performance concrete," Cement and Concrete Research, vol. 31, no. 4, pp. 595-601, 2001. 

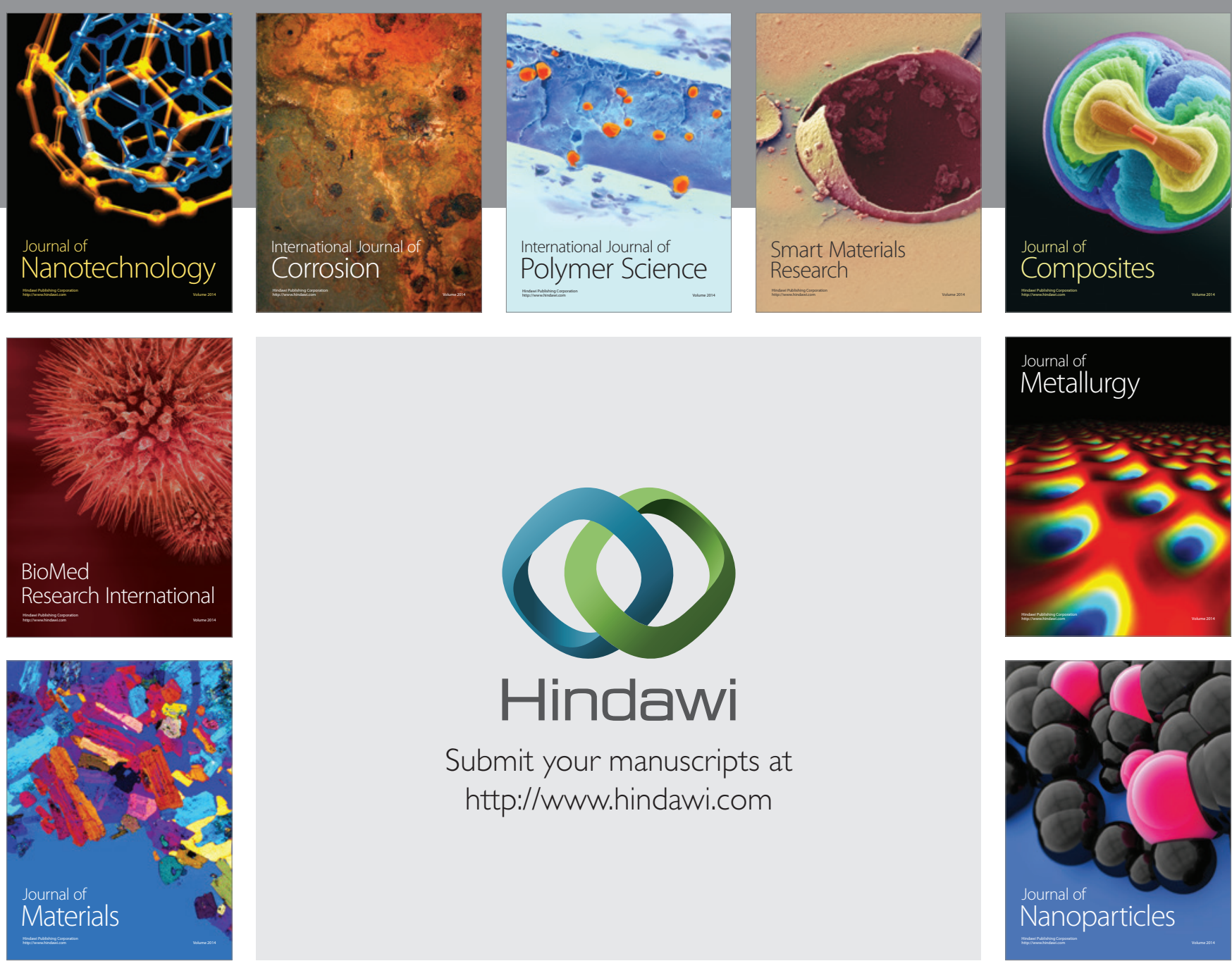

\section{Hindawi}

Submit your manuscripts at

http://www.hindawi.com

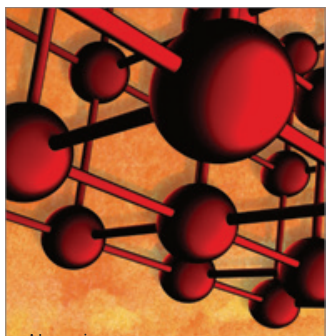

Materials Science and Engineering
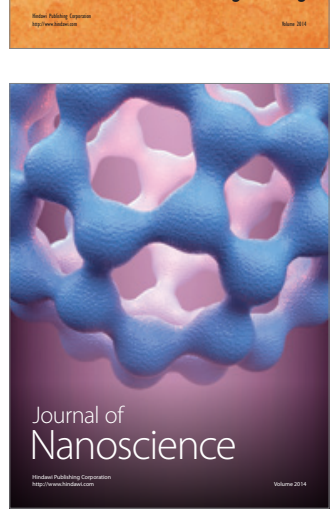
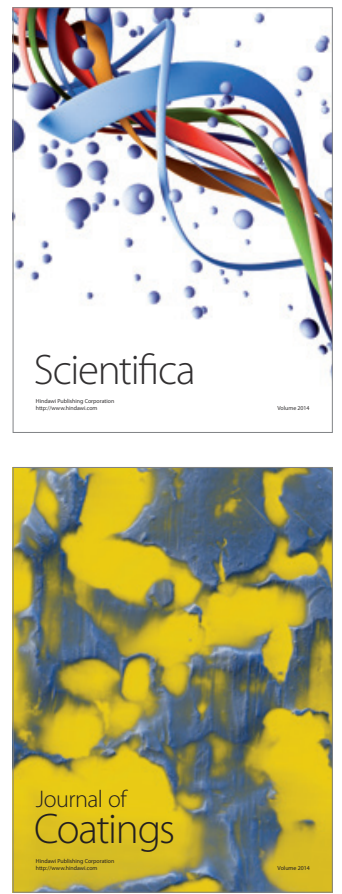
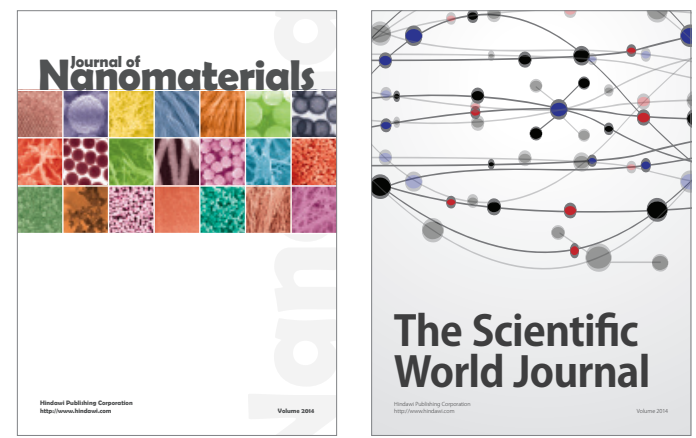

The Scientific World Journal
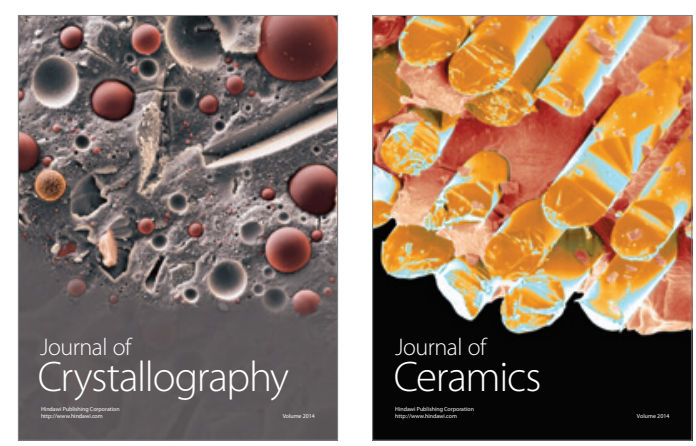
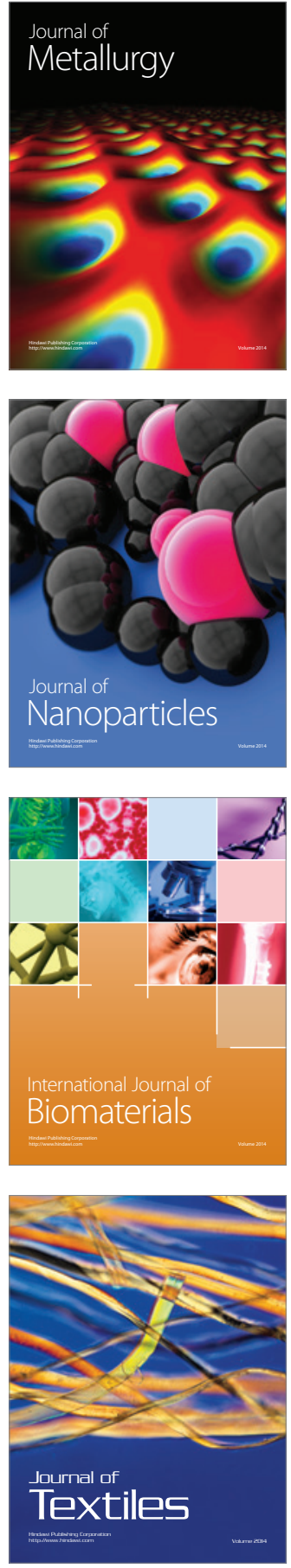